\title{
The influence of urbanization on energy consumption and carbon emissions mechanism
}

\author{
An Xu and Hua Xu
}

School of Management and Economy, Jingdezhen Ceramic University, Jingdezhen, 334000, China

\begin{abstract}
Although a lot of literature from the perspective of econometrics, the urbanization and energy consumption and carbon emissions has a strong correlation between, however the urbanization and the relationship between energy consumption and carbon emissions is a complicated problem, the influence of urbanization on energy consumption and carbon emissions is a complex mechanism, involving many levels and aspects of the economy. The impact of urbanization on energy consumption and carbon emissions more is through the indirect way, this article from economic growth, upgrade industrial structure and consumption, etc. to analyze the mechanism of urbanization impact on energy consumption and carbon emissions.
\end{abstract}

Keywords: urbanization; energy consumption and carbon emissions.

\section{The economic growth effect of urbanization and energy consumption and carbon emissions}

Urbanization is the process of economic development space aggregation and differentiation, although the urbanization has a strong policy action, with high correlation, but the urbanization and economic development as a carrier for non-agricultural industries are the main space city urbanization development on the one hand and non-agricultural industries agglomeration scale and level of economic development. Therefore, mainly affected by economic growth and urbanization affects the energy consumption and carbon emissions. Can be determined from the main factors of economic growth to analyze the influence of urbanization on energy consumption and carbon emissions. Urbanization by influencing the investment growth, human capital accumulation and institutional change and technological progress to influence economic growth, which affects the energy consumption and carbon emissions.

\subsection{The investment growth effect of urbanization and energy consumption and carbon emissions.}

Urbanization has investment growth effects. On the one hand, the city is factors of production and industrial agglomeration, labor market development is relatively perfect, more employment opportunities, on the other hand, urban wage rates are higher than rural wage rates and urbanization with higher income effect, increase the income of the residents into savings and consumption, therefore, urbanization by income increase lead to more investment supply and consumer demand. Since China's reform and opening up, along with the advancement of urbanization in our country, the improvement of people's income, household savings in China is in the growing condition, has gradually become the main force of China's capital formation. In addition, the urbanization is often accompanied by a large number of urban infrastructure and residential investment, stimulated the iron and steel, cement, chemical industry and energy industry development. Ji 20 since the 90 s China's economic growth, mainly supported by strong investment demand, therefore our country urbanization through the contribution of investment growth effect on economic growth.

Investment affect the total energy consumption and energy efficiency, which affect the carbon emissions. Fixed asset investment growth is the main reason to promote the growth of China's energy consumption (o), 2009). Mass of fixed assets investment project basically needs to consume large amounts of energy, after completion of the performance in the construction process and the consumption in the daily operation; Investment in fixed assets of the large amount of investment to promote economic growth and the income of workers is greatly increased, in turn leads to the rapid increase of energy consumption; Through investment in fixed assets, scale economy and technological progress, and improve the efficiency of energy conversion, change the industry pattern 
of energy input and output, improve the energy efficiency. This urbanization by influencing the investment will affect the energy consumption and carbon emissions.

\subsection{The human capital accumulation effect of urbanization and energy consumption and carbon emissions.}

Urbanization is the cumulative effects of human capital. City has a form of human capital advantage. Urban industry is numerous, workers can take advantage of the opportunity, also prompted for urban residents will deepen the human capital investment; Urban incomes increase, especially human capitalization income increased significantly, directly stimulate the appetite for investment in education, promote the formation of human capital; City based didn't give the good education, to make urban education opportunities more; In addition, complex diverse city environment is conducive to the formation and accumulation of human capital, the knowledge spillover effect, also stimulate the increase of the human capital investment on education.

The modern economic development speed and quality, mainly depends on the abundance of human capital. Human capital advantage is able to apply professional knowledge master modern production equipment, engaged in economic and social activities with high efficiency, high-quality labor can not only enhance the labor efficiency, technology innovation, discovery, and create alternative way to improve energy consumption structure, such as energy to overcome the "bottleneck" factor, and can play a greater configuration in production activities, coordination and creation ability to improve the efficiency of energy use, such as human capital can be directly enhance and improve the effect of the material capital, and to reduce the energy waste phenomenon in the process of production and reduce the energy consumption intensity, promote economic growth from extensive to intensive changes. In a word, human capital accumulation is beneficial to reducing energy intensity and improve the efficiency of energy utilization, reducing energy consumption and carbon emissions.

\subsection{Effect of the technological progress of urbanization and energy consumption and carbon emissions.}

Urbanization also has the effect of technological progress. Relative to the countryside, city for technology innovation to provide more favorable environment and conditions, therefore, the technology innovation are mostly gathered in the city. First of all, the city has a form of human capital advantage. City as a high density of economic activity in the region, the different crowd to a more extensive close interaction between, because cities have better education foundation didn't give cause city residents to receive more education opportunities, at a given level of inputs and technology condition, the level of urbanization can increase economic efficiency by producing cluster effect, also can promote technology innovation by the spillover effect of urbanization and increase economic efficiency (Luesa, 1988; Glaeser, Edward, et al, 1992). By improving the agricultural and industrial technology level and the development of new and high technology industries such as information industry, urbanization promoted the technological progress (Cheng Zhizhong, 2002). Secondly, the city has the advantages of diversity and specialization. Different people, businesses, industries gathered in the cities, forming the diversity of the urban environment, conducive to different industries and collision, field personnel to communicate with each other, promoted the generation of new knowledge and new technology. A variety of highly specialized enterprises gathered in the city, and realize the Labour market, information and internal contact, such as resource sharing, which generates positive externalities.

Technological advances affect energy consumption and carbon emissions. The new economic growth theory and the study of knowledge economy, technological progress and technological innovation is the core of modern economic growth momentum. And technological progress and technological innovation can increase the per capita income and promote the rapid expansion of economic scale, resulting in energy demand rapid increase accordingly, and technological progress to improve energy efficiency, and indirectly promote the increase of energy demand. In addition, in addition to affect economic growth, in turn, affects the energy consumption and carbon emissions, technological progress is the main reason for the industrial sector energy efficiency (Li Lian water, 
2006), technology progress is the main reason for decline in energy intensity in China since the reform and opening up (Stern, 2008), technological progress is the main way to energy supply and demand structure optimization. In a word, technological progress by influencing the economic growth, in turn, affects the energy consumption and carbon emissions.

\section{The conversion of industrial structure effect of urbanization and energy consumption and carbon emissions}

Urbanization also has the effect of industrial structure transformation. City into a industry from primary industry to the second and third industry has created favorable conditions. The evolution of industrial structure is generally follow the rules, economic resources from the primary industry to secondary industry and then transfer to the third industry, in the process of industrial structure upgrade and optimization, production resources gradually from low value-added industries of high value-added industries. Urbanization is the shift between the labor force in the industry, is the labor force shift from primary industry to the process of the second and third industry. The advance of urbanization needs the development of the second and the third industry, need corresponding transfer of rural surplus labor force. Relative to the first industry, the second and third industry needs more Labour. Relative to the primary industry, secondary industry and tertiary industry in the city to reduce the transaction cost, is beneficial to the optimization of industrial structure; The development of urbanization, but also to gather effect and scale effect of the play, can also speed up the industrial structure optimization. With the first - think clark theorem, in the process of economic development, industrial structure of center of gravity, in turn, the first, second and third industry development gradually transfer order. In the population and other factors of production in the process of transition from rural to urban, productivity revolutionary change, large-scale industrial structure adjustment. As a result, the process of urbanization is often accompanied by industrial structure optimization, optimization and upgrading of industrial structure based on the urbanization, urbanization is an important carrier of adjustment of industrial structure upgrade. In general, the proportion of the second and third industry in the whole industrial structure is higher, the higher the level of urbanization.

The second industry and the tertiary industry is the main driving force of urbanization, the urbanization and promote the second industry structure upgrading and the development of the tertiary industry. Kuznets summed up the modern economic growth process of industrialization and urbanization, industrialization and urbanization is the twin-engine of modern economic development. The agglomeration economy effects and scale economy effects of urbanization provide a good external condition for industrialization, the further development of industrialization to promote the development of urbanization. The relationship between such as $\mathrm{S}$ type curve. The second and third industry expansion effect of urbanization is different, the former is mainly reflected in the amount of urbanization, while the latter is embodied in the quality of urbanization. Industrialization is more is the expansion of city scale and the number of cities increased, while the development of tertiary industry to perfect the hardware and software facilities and improve the quality of people's life. In addition, the third industry is mostly knowledge technology-intensive and labor-intensive industries, the second industry's ability to absorb labor will be accompanied by a downward trend with the increase of organic composition, relative to the first and second industry, the tertiary industry can absorb more labor employment, the development of the tertiary industry is a major driving force for the later stage of urbanization. 


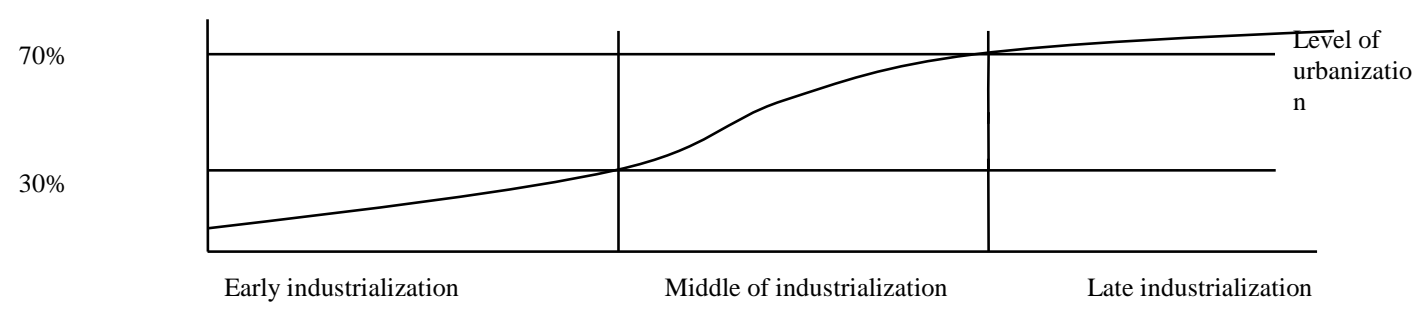

Figure 1 Development stage of industrialization and urbanization development level

With the development of urbanization, the second and third industry production value accounts for the proportion of total output increasing, the second and third industry employment to total employment population continues to increase, the second industry output value of output is greater than the tertiary industry, secondary industry employment proportion is slightly lower than the tertiary industry employment proportion, the tertiary industry output value proportion and employment growth should be faster than the second industry. These instructions, over the past twenty years, industrialization development of urbanization process has played a major role, but the role of the third industry in the development of urbanization is increasing.

The total energy consumption is affected by the industrial structure, mainly because of three industrial energy intensity and industrial gross weight is different. See from figure 3.2, three are in increasing the total energy consumption of industry, the second industry for most of the total energy consumption accounts for the total energy consumption, energy consumption of the third industry also account for a certain part of the first industrial energy consumption is relatively small. The second and third industry energy consumption growing is the main reason for the increase in energy consumption in our country. See the energy intensity of all significant reduction in figure 3.6, indicates two industrial energy efficiency both increase greatly, mainly because of economies of scale, technology advancement of the urbanization and more efficient allocation of resources. The energy intensity of the second industry is the largest, followed by the third industry, the first industry. The second and third industry since 1991, the main reason for the growth of energy consumption because of the second and third industry rapid development, the development of significantly faster than the speed of energy intensity fell. The rapid development of the secondary industry is the result of our country to speed up the process of industrialization, the intermediate stage of the industrialization stage of heavy industry, heavy industry stage of industrial development for energy dependence is stronger. The increase of energy consumption of the third industry, mainly transport energy consumption and the rapid increase of building energy consumption.

The advance of urbanization is advantageous to the urban non-agricultural industries internal structure optimization. Higher urbanization level of national experience has shown that urbanization lead to the inside of the non-agricultural industries according to the light industry - heavy industry order sequence evolution of the services sector. In the early stages of industrialization and urbanization, the light industry become a dominant industry, mainly because it only needs to produce simple raw materials and low capital investment; After entering the intermediate stage of industrialization and urbanization, as a result of the consumption demand structure upgrading and technological progress, the city industrial structure gradually from light industry to heavy industry transfer; Into the late stage of industrialization and urbanization, the third industry become the dominant industry in this city. Urbanization and industrialization stage characteristics, namely, medium in the early industrialization, per capita GDP and urbanization level is not high, the water along with the development of the industry and improve the urbanization, urbanization and industrialization was a positive correlation; , late in the industrialized, with per capita GDP increase, the people increase the demand for services, services in the GDP proportion is also on the rise, industrial as a share of GDP is low, while the level of urbanization gradually increase, the characteristics of urbanization and industrialization present negative correlation (China's economic growth and macroeconomic stability research, 2009). 
Changes of industrial structure is one of the important factors affecting energy consumption (Stan, 2003). Different industry of energy consumption index. In 2008 the first, second and third industry in our country's energy consumption index were $0.3,0.3$, about 03600 tce/one hundred million yuan. Shows, the energy consumption index of the second industry's largest, and the third, the industry energy consumption index is relatively small. The adjustment of industrial structure upgrade by influencing the comprehensive energy consumption index, in turn, affect the overall energy consumption level. If energy consumption index of industry in the national economy, the greater the proportion of the total energy consumption level will be higher, the opposite. In addition, the adjustment of industrial structure on the reduction of energy consumption intensity is negative (qiao-sheng wu, jin-hua cheng, 2006).

Different industrial structure, energy consumption structure is also different. According to statistics, in 2008, the first industry consumes $4 \%$ of the coal, $7 \%$ of its oil and $7 \%$ of the electricity, the second industry consumes nearly $86 \%$ of the coal, $86 \%$ oil and $80 \%$ of electricity, the third industry consumes around $3 \%$ of the coal, about $50 \%$ of the oil and about $10 \%$ of the electricity. Different energy coefficient of carbon emissions, the carbon intensity of result in different industries is different, the carbon emissions of different industries is different. Therefore, urbanization lead to the evolution of industrial structure upgrade, ultimately affect the carbon emissions. According to three industrial energy consumption in China energy statistical yearbook carbon emissions, is calculated respectively divided by all industry output value to obtain carbon intensity, the second industry and the tertiary industry growing carbon emissions, to speed up the growth rate after 2002. The second industry carbon emissions accounted for nearly $75 \%$ of the total carbon emissions, the third industry carbon emissions accounted for about $20 \%$, the first industry accounts for less than $5 \%$. All three carbon intensity of industry present a downward trend, from 1991 to 2008, the first industrial carbon intensity fell by $83 \%$, the second industry has fallen by $82 \%$, the third industry has fallen by $86 \%$. Urbanization led to the decrease of the three industrial carbon intensity and carbon emissions increase, the size of the main cause is a decline in carbon emissions lower than three times the size of industrial expansion.

\section{The consumption upgrade effect of urbanization and energy consumption and carbon emissions}

Urbanization and consumption upgrade influence each other and promote each other. Real micro to urbanize the reason: urban and rural residents' consumption structure changes make their demand for non-farm products continue to increase, and lead to the change of the industrial and agricultural production and urban and rural employment structure, rich labor transferred from rural areas to urban employment, under the action of increasing industrial scale effect, the per capita net income of urban residents is higher than rural residents per capita income growth, and further attract surplus labor transferred from rural areas to urban employment, so cycle accumulation, so as to push forward the process of urbanization, therefore itself to improve the level of consumption, the improvement of urban and rural residents as a result of the desire of the consumption structure between urban and rural employment structure change and the basic microscopic dynamics evolution of urbanization. Urbanization influences consumption through the following several aspects: content, the consumption structure change influence social consumption psychology, lead to the third industry operation pattern transformation, the residents' consumption "crowding out" and "accumulation effect", influence consumption "differences between urban and rural areas" and "regional differences" (Yang tao, 2006). Consumption is mainly controlled by income, and with the improvement of the level of urbanization, urban residents' income increasing, urban residents to the refrigerator, the increase in consumption of durable goods such as cars, televisions, lead to urban residents consumption upgrade, therefore, urbanization will help to boost consumption growth and upgrade. In a word, on the one hand, the rapid advance of urbanization process in China is the positive factors to promote changes in China's consumption rate; , on the other hand, China's urbanization rate is low, 
the urbanization lags behind industrialization process, and low consumption rate in our country, the important reason for the imbalance between investment and consumption.

On the one hand, the rapid advance of urbanization process energy consumption of urban residents life has a positive role in promoting; On the other hand, the current our country residents life energy consumption in the process of urbanization has much upside, this to our country by stimulating consumption to expand domestic demand to promote economic growth and urbanization has created good conditions.

\section{Summary}

Relationship between urbanization and energy consumption and carbon emissions is a complicated problem, urbanization is not a direct impact on energy consumption and carbon emissions, the use of data and theoretical analysis in this chapter how urbanization through economic growth, the upgrading of industrial structure evolution and consumption upgrade among factors such as energy consumption and carbon emissions. Urbanization by influencing the investment and economic growth factors such as human capital and technological progress, which affects the energy consumption and carbon emissions. Urbanization by adjusting the industrial structure affects the energy consumption and carbon emissions. Urbanization causes consumer upgrades, and then affects the energy consumption and carbon emissions, the data table urbanization in our country did not lead to strong consumer upgrades, so by impact, in turn, affects the energy consumption and carbon emissions are limited.

Colleges and universities in jiangxi province department of education project of humanities: jiangxi dynamic mechanism and realization path of urbanization in the new study - based on the perspective of innovation drive.

\section{References}

[1] Yang tao. Urbanization promotes consumption should become an important strategy to expand domestic demand. HTTP / / finance. Sina. Com. Cn/stock/t / 20060821/0000871036. SHTML, 2006

[2] Qiao-sheng wu, jin-hua cheng, wang hua. Changes in energy consumption in the process of the industrialization of China based on the empirical analysis of measurement model $[\mathrm{J}]$. China industrial economy, 2005 (4) : 30 to 37

[3] Stan. Energy efficiency improvement in the process of economic growth in China [J]. Journal of economic research, 2002 (9) : 49-5

[4] Cheng Zhizhong. [D] the theory of urbanization and economic growth: [Ph.D. Thesis]. Sichuan, chengdu, southwest university of finance and economics, 2002.

[5] Zong-xian feng Chen regional energy carbon emissions and decoupling of economic growth trend analysis [J]. Journal of anhui, hefei, east China economic management, 2015 (1) : 50-54. 